\title{
Extending the Role of FERP Mall for More Flexible Softy for Satisfying the End-User-Enterprise
}

\author{
Evan Asfoura, Naoum Jamous, Gamal Kassem, Reiner Dumke \\ Otto-von-Guericke-Universitaet Magdeburg, Germany
}

\begin{abstract}
The federated enterprise resource planning systems (FERP systems) based on Web Services (WS) is a new business idea, which should be implemented in an appropriate business model. This idea came to meet the growing needs of small- and medium-sized enterprises (SMEs) with regard to the relatively expensive business software solutions through the distributed ERP systems based on Web services.

An intermediary business model (broker) in this case, is meaningful and appropriate. This intermediary integrates the business functions required by users in an appropriate business process model as a workflow model. This work aims at extending the role of the intermediary in three Scenarios by the coordination of the activities between the FERP WS Providers and the end-user enterprise to satisfy the different required security levels from these enterprises.
\end{abstract}

\section{Introduction}

The federated enterprise resource planning systems (FERP systems) based on Web Services (WS) is a new business idea, which should be realized in an appropriate business model.

Why and what is FERP system?

FERP system aims to solve several problems, which appear in connection to the conventional ERP complexity, like [2, 8]:

Not all installed components are needed

High-end computer hardware is required

Customizing is expensive.

As a result, ERP systems become too costly for SMEs.

A federated ERP system (FERP system) is an ERP system which consists of system components distributed in a computer network. The overall functionality is provided by an ensemble of allied network nodes that all together appear as a single ERP system to the user.
Different ERP system components can be developed by different vendors [1][2][3][8] as shown in Figure 1 [1]:

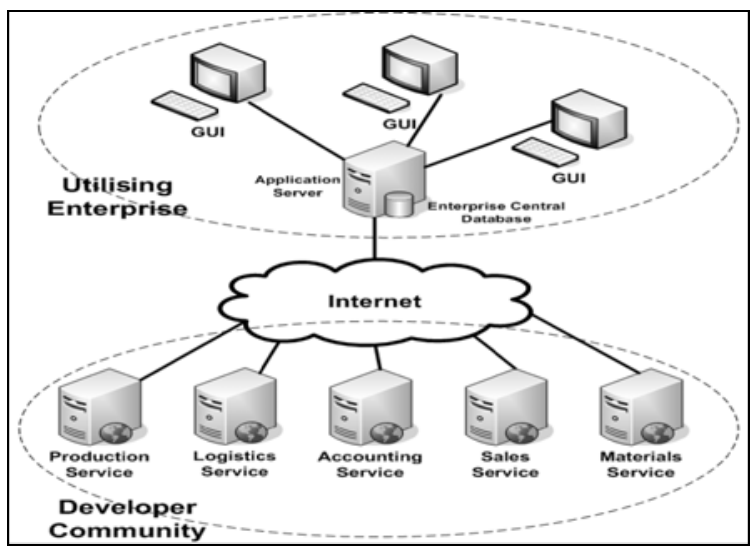

Figure 1. Architecture of FERP- Systems

FERP systems based on WS aim to fulfill the requirements of small- and medium-sized enterprises (SMEs) and to solve various problems concerning the conventional ERP system [1,2,3].

Web Service is a software system designed to support interoperable machine-to-machine interaction over a network. It has an interface described in a machine-processable format (specifically WSDL). Other systems interact with the Web service in manner prescribed by its description using SOAP-messages, typically conveyed using http with an XML serialization in conjunction with other Web-related standards [4].

The main specifications for FERP systems could be summarized as the following [3]:

- A FERP system consists of standard installation and system of FERP application components. The functionality of the application components are provided as needed as a set of standardized services from different providers, therefore competing offers are possible. 
- Suppliers can choose a service offer, depending on their expertise.

- User companies can arbitrarily change the service providers.

- ERP processes can integrate different vendors and be offered separately.

- Usage-based billing models for FERP services are possible.

These properties should be taken into account when we design or propose a business model for the exchange FERP's components as WS, to meet the appropriate one.

What is business model?

We can see through the literature review, there are many definitions of business model, but the best known one is the definition of Timmer [12]:

A business model includes:

- Architecture for the flow of products, services and information.

- A description of the various actors and their roles.

- A description of the potential benefits for the individual actors.

- A description of the revenues.

In other words, business model characterizes the actors, their roles and the goods and cash flows between them.

Why and what is FERP Mall?

There are more than one customer and provider of the ERP components in this business model. Therefore, this business model serves as a commercial intermediary between the providers and customers. This intermediary presents the ERP components of different providers and organizes a cross vendor to satisfy the functionality demanded by the customers [13]. An intermediary is an entity that stands among suppliers and customers and can act actively or passively. Besides the added value of the intermediary's experience, the mediation between customers and providers is relevant because the search process by such an intermediary is cheaper than a direct single search process. That includes emall as well as e-auction [11].

In ERP auction, the customer (user or company) should sign several contracts, if his/its requirements are covered by different ERP WS providers. That means that each provider is partially responsible to the user and there is no single "one" responsible party with which the customer could deal in case of failure or any accident. As a result of this problem, besides the high prices of ERPs software, we consider this possibility practically inapplicable [5].

As a result, we say that an ERP's E-mall as an intermediary business model between the providers and the end-customer is the reasonable and appropriate business model type, which can fulfill the needs of (SMEs) through an appropriate adaptation [5,16]. This e-mall contains several professional ERP shops and offer support services in addition to the supplying role of FERP WS as other shops, which are necessary for this mall as integrators. The integrator provides the FERPReference workflow model which represents all possible business scenarios of an enterprise (see Figure 2):

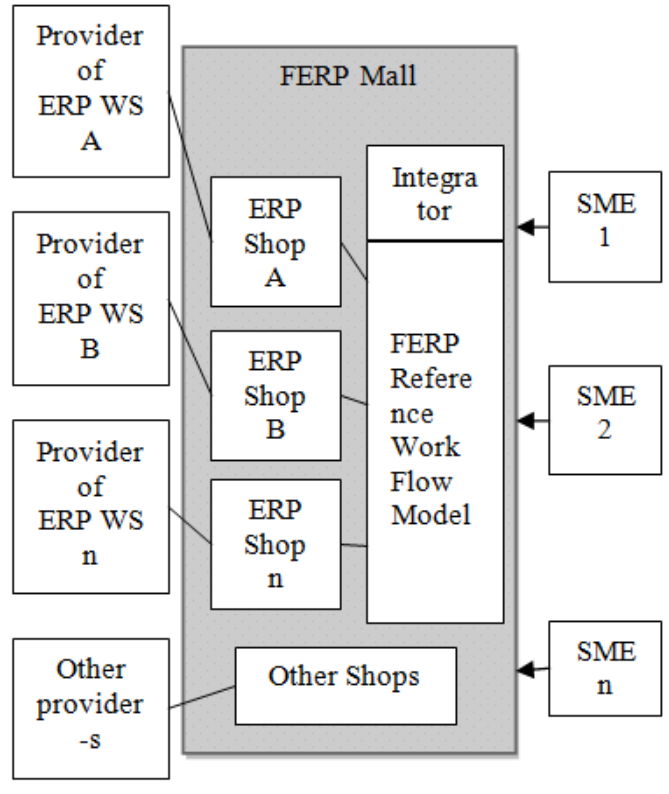

Figure 2. FERP Mall

Compatibility with other providers motivates ERPs' providers to contribute in such malls [5]. In addition, the higher level of trust in large companies could motivate both customers and providers to deal with such malls. Then this business model contains three actors (supplier, mall operator "mediator" and customer), which act along the value chain of FERP (see Figure 3):

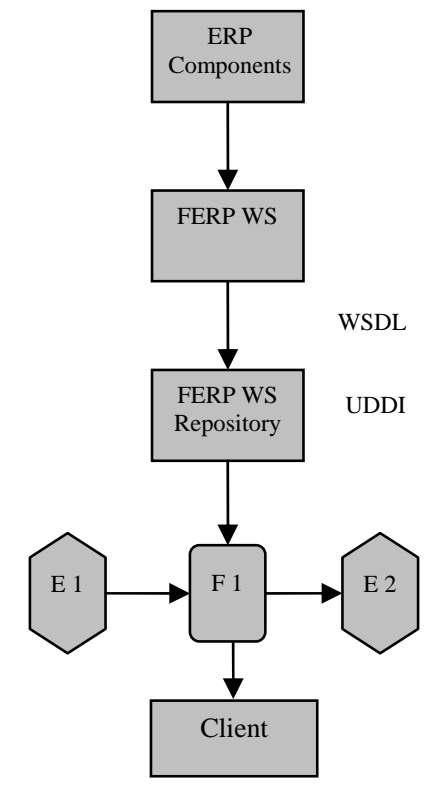

Figure 3. The value chain of FERP 
This work describes three different Scenarios for the behavior of the intermediary between the Providers and customers to increase the security and trust to satisfy the different required security levels from the customer-enterprise by marketing the FERP functionality.

So, we present in the second section classification of the security-levels of the FERP customerEnterprise; in the third section, the agreements between the intermediary and the client (user) as a process-level agreement (PLA); in the fourth section, the agreement between the intermediary and the provider of a service as service level agreement (SLA); in the fifth section, the description of the three behavior-scenarios during the transaction phase between the actors with the implementation of an example; in the sixth section, we evaluate the benefits from FERP mall. This work is summarized in section seven.

\section{Classification of FERP user- enterprises according to the needed security-levels}

SMEs ,as customers' FERP Mall,, could be different according to the size and / or to the Enterprisesectors to which the required ERP functionality belongs. For example, ERP functionality sectors are classified as follows (Abel et al, 2007):

- $\quad$ Production planning and controlling

- Accounting

- Logistics

- $\quad$ Sales and distribution

- Human resource management

- Quality management

- $\quad$ Project Management and

- Materials management

In the side, the sizes of the enterprises are different according to the number of employees in these enterprises (see Brehm et al, 2008).

Then, the FERP user-enterprises could be divided according to business sector and size into three categories:

- Enterprise from type A ----------- With lesser security level

- $\quad$ Enterprise from type B ----------- With a higher security level

- $\quad$ Enterprise from type C ---------- With a higher level of security and / or with the aim of using the external functionality as part of the internal ERP system.

Each user enterprise can decide to which category it belongs to based on the comparison between the cost and required security.
The agreements between the Actors should be identified and explained through the information and negotiation phase for all scenarios. These Agreements are [18]:

- Intermediary-provider agreement in the information phase.

- Intermediary-customer agreement in negotiation phase.

\section{Intermediary-customer (PLAs)}

agreement

One of FERP mall aims is to have one responsible entity or personality to the user company or the customer. The relationship here will be business-tobusiness and the security is relatively good where the two actors are known. The user companies could need many functionalities offered by different providers and will be integrated in the form of one or more processes by the intermediary to reach the suitable FERP solution. Therefore, the intermediary acts as an integrator and in the same time plays an advertising roll through FERP web service repository (see Figure 4).

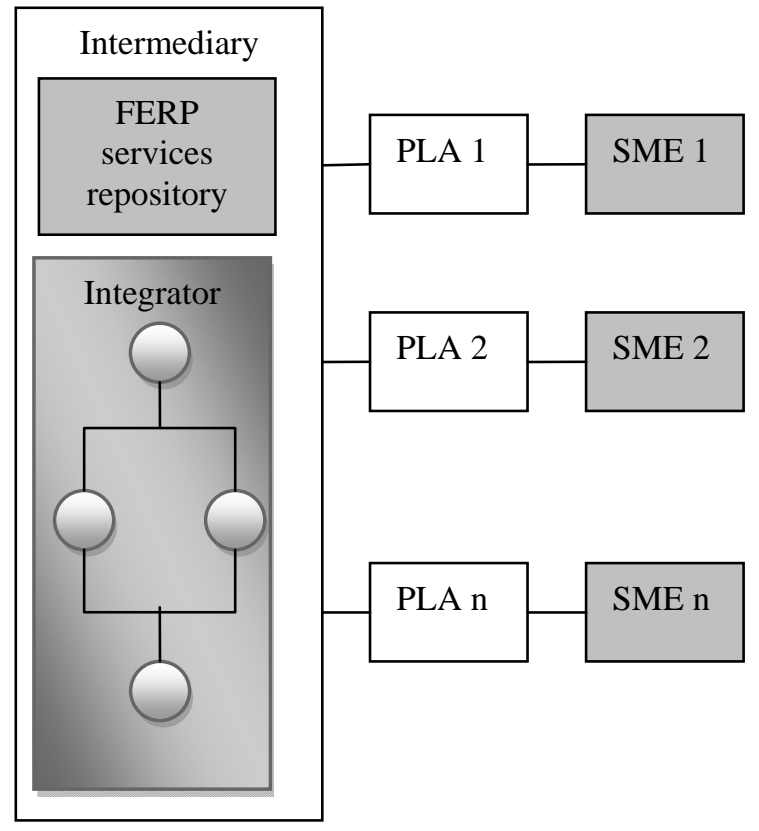

Figure 4. Intermediary-providers agreement

The intermediary provides the user with the desired FERP processes (process level) and he is responsible in case of non-compliance.

Business process means: "The success-and basic business activities which serve the enterprise goals and enterprise success, and describes the essential tasks that characterize the business of a company" [15]. 
In FERP Mall, user companies are users (clients) of FERP processes, which are organized by the intermediary. This intermediary integrates FERP WSs as a workflow model. This organizing acts or orchestrations are implemented by BPEL (Business Process Execution Language). This means we can differentiate two categories in the FERP process from the intermediary perspective:

- WS BPEL program, which should be implemented by the intermediary itself "internal part".

- $\quad$ FERP WS, which are produced by different suppliers “external part”.

The intermediary (as integrator) should not take the risk of complying the external part "the FERP WS" with regards to the client through the signed PLA. Therefore, a third section takes part in the agreement, between the intermediary and the providers.

\section{Providers-intermediary agreement (Service Level Agreement SLA)}

The intermediary should insure itself against the providers through the service level agreements until it can comply the process level agreement (PLA) with the client (see Figure 5), then the service levels are the input for the process level.

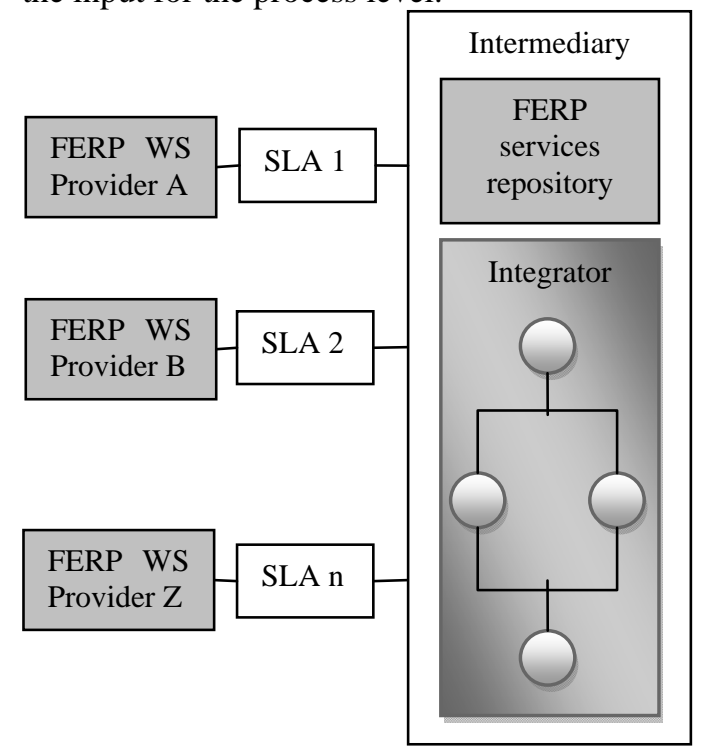

\section{Figure 5. providers-intermediary agreement}

An SLA is a required agreement between users of services, "clients", and a service provider about the quantity and the service level in form of a certain amount and quality within a defined scope [9].

SLA guarantees that the client receives the service for which he paid, and obtains the service provider to fulfill the contract requirements regarding the client. The SLA violation has significant financial consequences [6]. In our business model, the providers are responsible to the intermediary for the SLAs.

SLAs consist of the following main components; parties or actors, service level indicators (SLI), Service level measurement tools, and the penalties [6].

1. SLA parties: The most important components of SLA are the parties (actors) due to the fact that they identify the other components of the agreement (SLA), and the SLA responsibilities will be distributed between them. Therefore, it is so important to determine the actors for each business model as a first step. In our business model, there are three parties or actors (providers, intermediary and end-customer enterprises) as described before in Section 1.

2. Service level indicators (SLI): In every business process end-customer enterprise needs one or several FERP WS from different providers (as the outsourced function) and it could be that the same FERP WS is provided by several providers. The selection of FERP WS mainly will be based on the quality and the cost of these services. Cost and quality information of services should be described with different SLIs as marketing parameters with a target value for each indicator in a standardized format. This description should be evaluated automatically, because that is a prerequisite for the automated selection and integration of WS at runtime [10]. SLIs could be described as dynamic service properties in addition to the static properties such as URL, name and type of services by the registration of the Service. These dynamic properties reflect the quality and performance, and change at runtime [6]. The static and dynamic properties of the WS could be in some vocabularies in the universal description discovery and integration (UDDI) of the FERP mall. up Microsoft Word.

3. Service level measurement tools and the penalties: the definition of measurement tools and methods simplify the testing of SLAs. The first step after the description of SLI is to identify measurement elements such as targetvalues, is-value of the SLI, difference and penalties.

- Target-value: The Penalties are the financial consequences "in some cases could be intangible", which the provider should compensate in case of the deference. These penalties are determined by the intermediary in the contract with the provider. But it is also relevant to determine the responsibilities of this difference in the context of FERP system. It is the value of an indicator, which is identified in the contract between the provider and the intermediary. 
- Is-value is the value, which is created by the provider. This value can be measured by the service provider, the customer and / or the intermediary with appropriate metrics.

- The difference represents the differentiation between IS-value and target-value ((ISvalue) - (target-value))

- The Penalties are the financial consequences "in some cases could be intangible", which the provider should compensate in case of the deference. These penalties are determined by the intermediary in the contract with the provider. But it is also relevant to determine the responsibilities of this difference in the context of FERP system. The trust and security between the provider and the intermediary are lower, because the relationship here could be person-to- business. Therefore, the intermediary needs methods to test and ensure the quality of the offered services [14].

The intermediary can use appropriate payment systems for more assurance against the large number of suppliers, which is explained in the fourth section through the transaction phases by FERP Mall.

\section{The Role-scenarios of the actors along the Transaction phases in FERP Mall}

Transaction phases (information, negotiating and transaction phase) in this business model could be done online, as a result of the digital status of the offered goods. The action in the information and negotiating phases stay the same for all the scenarios but the difference appears in the transaction phase through using the form of the ERP functionality.

\subsection{Information phase}

The offer publishing begins when the provider sends the service information to the FERP mall operators (intermediary), and ends with signing the contract. The service information describes the static and dynamic properties of each operation of services: "a web service could include one or more operations" and describes the target values of the dynamic properties as a service-level indicator. The FERP Mall is known as a representative of the respective provider against the end-customer enterprise. In this phase, the intermediary can test the offers with appropriate methods.

\subsection{Negotiating phase}

The intermediary receives a demand request from the end-customer enterprise as FERP process with the desired quality referring to type of this customer (ex: type A, B or C). After that the intermediary, as mall operator, analyzes the required functionality within this process and the desired quality and sends the contract to the customer with the recommended list of providers, the target value of the process level and the cost per operation call for each provider. This phase ends when the customer sends back the signed contract to the intermediary.

\subsection{Transaction phase (delivery and payment) for customer from type $A$}

After signing the agreement between the operator and the customers, the operator permits the customer to use the chosen functionalities offered in the mall.

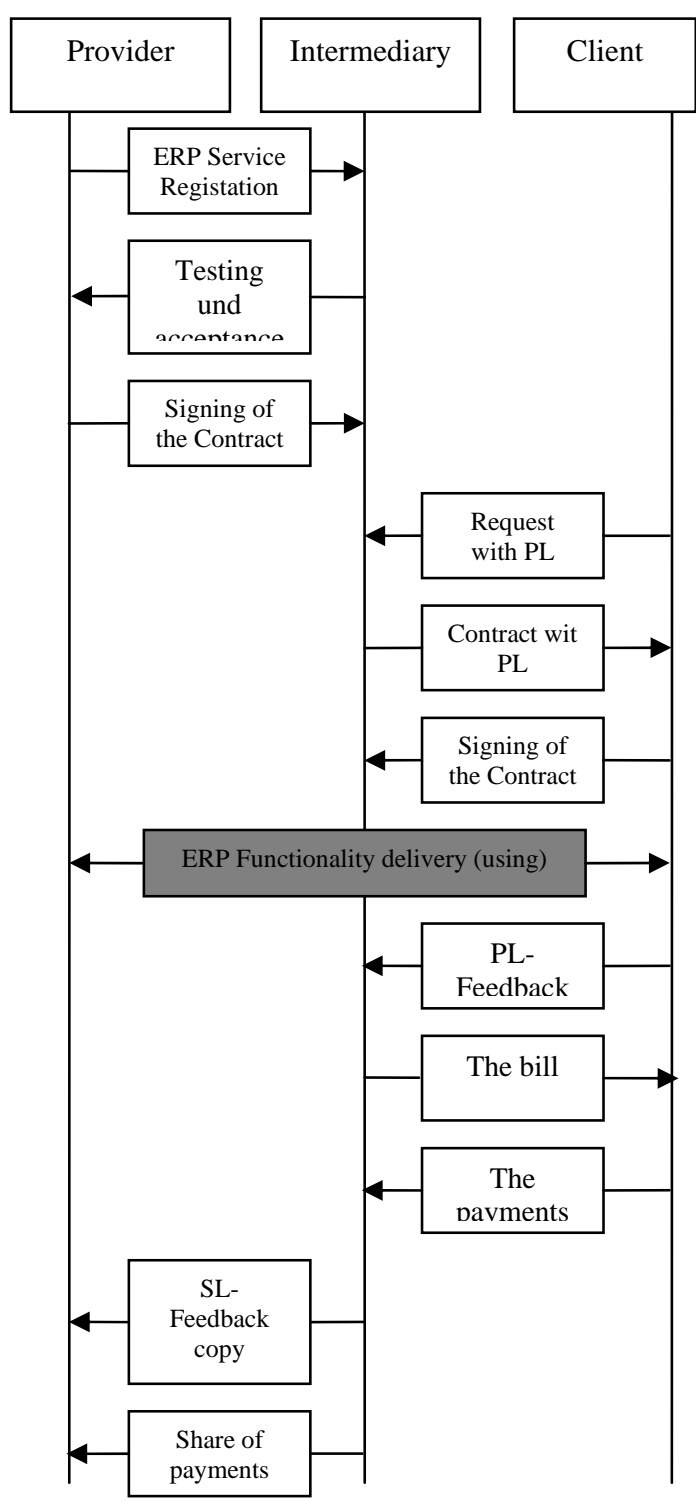

Figure 6. Transaction phases by FERP Mall for customer A 
After using the requested ERP, the customer reports to the intermediary whether the agreements are fulfilled or not point by point. Then, the operator "intermediary" sends a copy of this information to the providers and calculates the customer bill. This phase ends when the customer transfers the money and the intermediary transfers to each provider his part of money based on his participation and the quality of this participation. Here, we have to keep in mind that the providers hold the responsibility of the non-compliancy of the SLAs with the customer which is monitored and determined by the intermediary.

In this case, the FERP Mall looks as a shared company: each provider is a participant with its functionality, which is used by the customers (see figure 6).

This scenario could be more suitable for small enterprises since they do not need a very high security level. In consideration of the security solution, this has been proposed by Brehm, Marx Goemez and Rautenstrauch in [17][19][20]. But that may be not acceptable from the point of view of the enterprise which needs more security because of its functionality sector (ex: Banking sector). Furthermore, it does not allow the access or sharing of its data from unknown providers with low guarantee levels. Therefore, we present two other scenarios for this kind of enterprise in the following sections.

\subsection{Transaction phase (delivery and payment) for customer from type $B$}

In this case, the FERP mall (intermediary or mediator) informs the FERP WS suppliers about the customer type after the agreement with the customer. The provider then delivers the functionality-structure to the intermediary (mall) as a trusted party. After that the customer (the user company) uses the ERP functionality by calling the ERP WS operations by the intermediary. At the end of FERP process, the customer sends the information about the actual value (is-value) of the PL to the intermediary and the last one will send a copy to the provider.

The intermediary mediator calculates the costs and sends the bill to the customer. This phase ends when the customer transfers first the money to the intermediary and the intermediary then transfers the money to each provider. The money is distributed based on participation and the quality of participation. Here, we have to keep in mind that the providers hold the responsibility of the noncompliancy of the SLAs with the customer which is monitored and determined by the intermediary (see figure 7)

The enterprise from this type (B) has to pay more than the Enterprise from type (A) because the coordination of the activities and keeping the required functionality structures in case enterprise B makes the required role from the intermediary bigger than the role in case of enterprise A

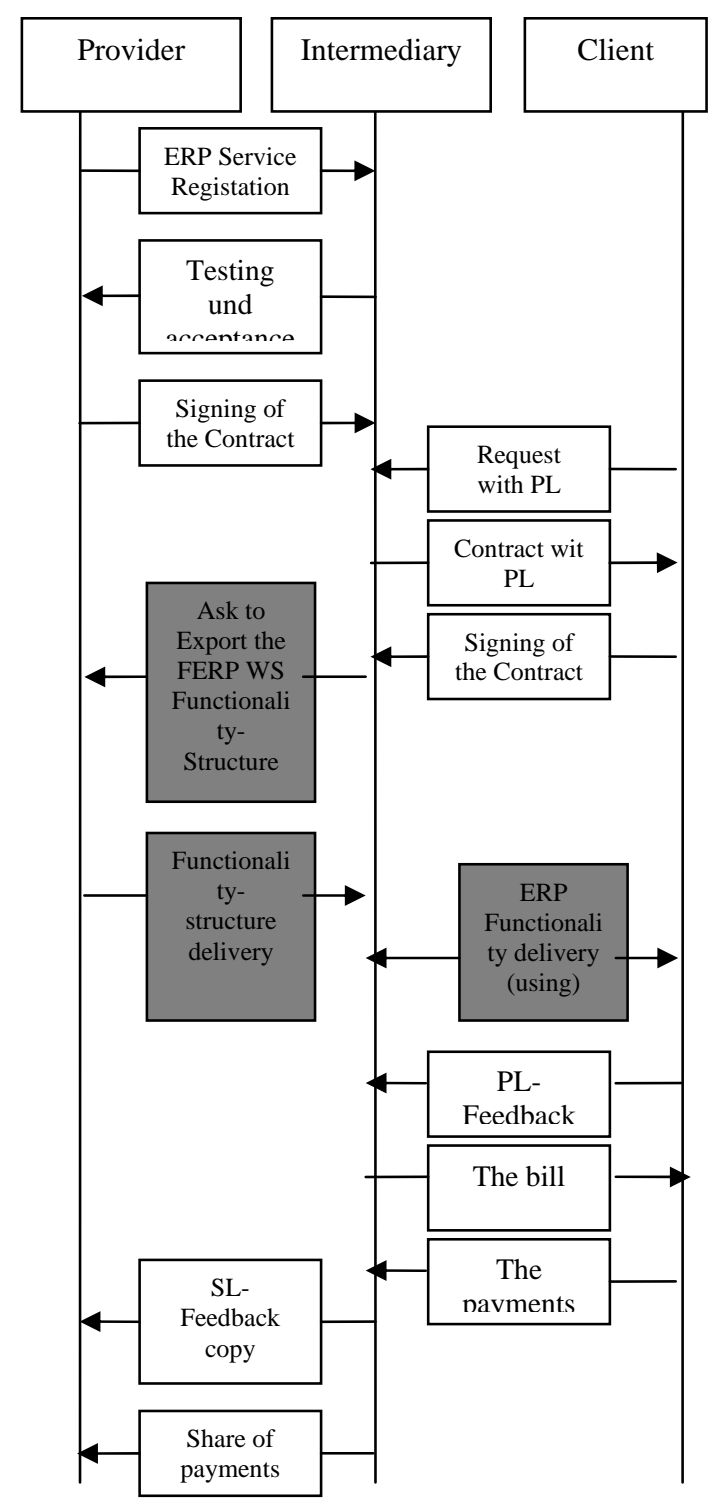

\section{Figure 7. Transaction phases by FERP Mall for costumer $B$}

\subsection{Transaction phase (delivery and payment) for customer from type $C$}

In this case, the FERP mall (intermediary or mediator) informs the FERP WS suppliers about the customer type after the agreement with the customer. The provider then delivers the functionality-structure to the user-enterprise directly as part of its internal ERP system. The user companies can use internally this case by calling the ERP service operations. Then, the customer sends the information on the actual value of the PL to the intermediary and the mediator will send a copy of this information to the provider. The intermediary calculates the quantity 
costs from the penalty taken into account noncompliance of the promised process levels and sends the customer the resulting bill. In this case, the payment basis on using the license of the FERP WSs functionality is the limited time. This phase ends when the customer transfers the money to the intermediary and the intermediary transfers a part of this money to each provider based on his participation and the quality of participation. Here, we have to keep in mind that the providers hold the responsibility of the non-compliancy of the SLAs with the customer who is monitored and determined by the intermediary (see Figure 8).

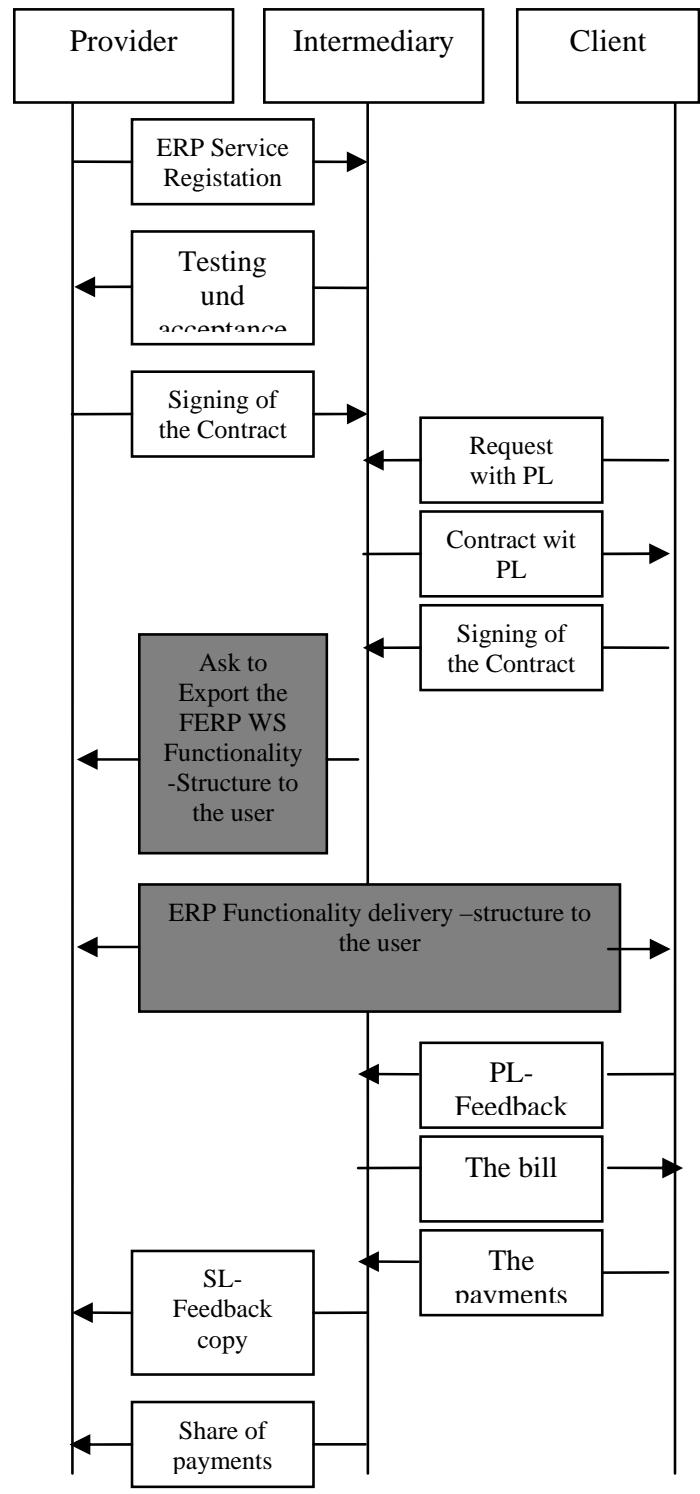

\section{Figure 7. Transaction phases by FERP Mall for costumer $\mathbf{C}$}

The enterprise from this type (C) has the highest security level but it has to pay more than the other enterprises from type A and B because:

- The needed end-Hardware for keeping the required functionality structures.
- The payment for the license of using the ERP Functionality internally from the userenterprise.

- More time will be needed for the replacement of the FERP WS when this WS goes down.

Then the user-enterprise can choose a suitable alternative from these three scenarios through the comparison between the related costs for each scenario and the needed security from this enterprise.

In the next section, we will describe an example for the interactive relationship between the respective FERP WS provider and the Intermediary for updating the delivered WS functionality-structure in case of the scenario B (and that can be done in case of the scenario $\mathrm{C}$ between the respective provider and the user-enterprise).

\subsection{FERP mall as trusted party for saving the user-enterprise dates}

We will present a platform and implementation protocol of a simple example about transfer the WS functionality and its updating to the mediator side. That will be transformed as standard web services through our future work. This section describes how to automate the process of requesting web services by the Mediator, implementing and submitting them back by the service provider (Developer). The transference process is done automatically through the web. The transference of web services also implies the transference of its entire resource .e.g. updated/new database tables. In order to start performing the task, the Mediator must first access the system's web site. This site was developed using jsp and java servelt and is served by the Tomcat server, which runs the programs responding to the Mediator requests. The new/updated services are submitted back to the Mediator which then can distribute them to the clients based on their request and need. Figure 8 illustrates the general overview of the interaction between the Mediator, developer and client.

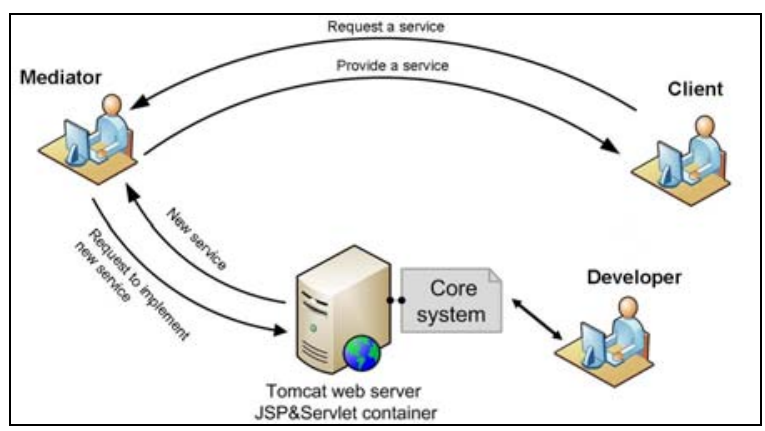

Figure 8. General overview of the interaction between Mediator, Developer and Client

The Mediator sends his request, through a web server to the developer. After the developer provides 
the new or updated service/services, the system submits the new or updated service to the Mediator. This new or updated web services will be placed automatically on the Mediator side. If the Mediator requested an update in the database for an existing service, the developer has to perform the update task. It is important that the update of the structure of an existing database table, for a service, will not lead to the loss of data on the Mediator side. As Figure 9 shows, the Mediator has the existing services, creates client data (client ID, Client name, Company and client address), searches client data and deletes an existing client. Let us consider this case, where the Mediator requests new services (Order service) from the Developer. The Mediator starts by requesting the new service by sending the Developer a full description of the new services .e.g. what the services are about, what the requested entry fields are and what is the exact task of the service. In our case, the Mediator is interested in having services to order items from the warehouse. The Mediator notifies the Developer that the required fields are Order ID, Client ID, requested item number and the availability of the item in the warehouse. The developer implements the service with its required database tables.

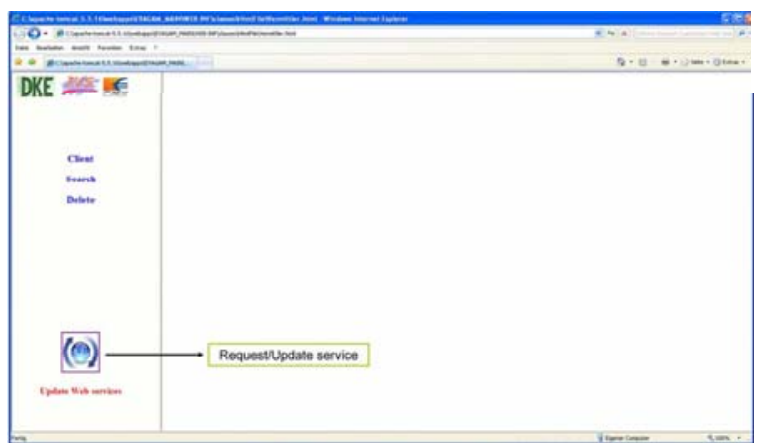

Figure 9. The current functionality of the system with the "Update Web Services

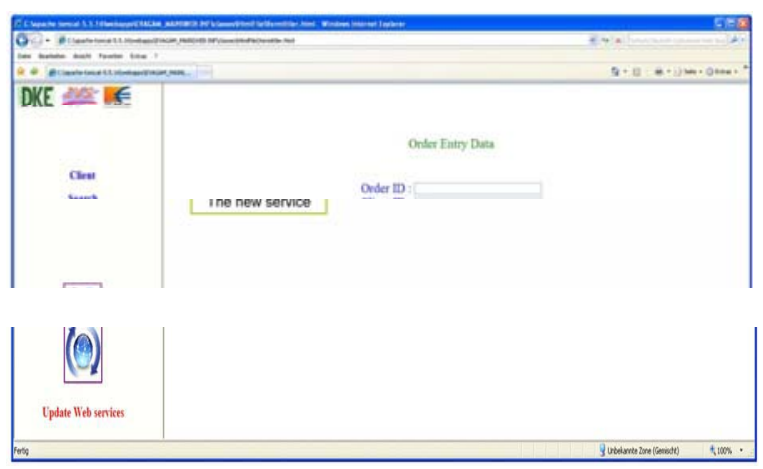

Figure 10. The new service with its functionality

As Figure 9 shows, the Mediator with a simple mouse click on the "Update web Services" button can start the update process; the system will check the new or the updated services on the Developer side and automatically transfers them to the Mediator side.

The system will notify the Mediator that the transferring process is completed. After this, the Mediator can refresh the system's website and thus the new service will appear in the system's main page which will be ready to use (see Figure 10).

\section{The evaluation of FERP Mall as market place for FERP WS}

In this section we will try to highlight the added values for both providers and clients using the FERP mall.

The added values for providers or suppliers:

- The compatibility with several FERP WS providers.

- Easier and faster way to reach the market, especially for small providers.

- $\quad$ Every Provider can offer services depending on selected competences [3].

- Increasing the level of trust where the business relation becomes business-tobusiness.

The added values for clients or customers:

- $\quad$ Pay only for the used components.

- $\quad$ FERP malls are more flexible to meet any change in the client's business processes.

- No need for high-end computer hardware [2].

- User companies can select the needed components from different providers directly through the mall as one ERP package.

- Benefit from the support services (exp. training and consulting) offered by the mediator.

\section{Conclusion}

In this paper, we presented the extending of the FERP mall role between the respective provider and the user-enterprise during the delivering phase after the agreement elements along the value chain for marketing of distributed FERP components based on WS. The FERP Mall coordinates the activities between the other actors through three alternative scenarios. Every user-enterprise can decide the appropriate scenario according to the needed security level with considering the related costs. In all these scenarios only the respective provider has the right to update the old version of his provided WSs and to submit the new version for the other parties.

\section{References}

[1] S. Abels, N. Brehm, A. Hahn, and J. Marx Gomez, “ Change management issues in federated ERP-systems - 
An approach for identifying requirements and possible solutions,.. International Journal of Information Systems and Change Management (IJISCM) 2006, 1, 318-335.

[2] N. Brehm , and J. Marx Gomez, “ Federated ERPSystems on the basis of Web Services and P2P networks,,. International Journal of Information Technology and Management (IJITM) 2007.

[3] N. Brehm, and J. Marx Gómez, “ Web Service-basierte Referenzarchitektur für Föderierte ERP-Systeme,,. In: (Pietsch, T.; Lang, C.V. Hrsg.): Ressourcenmanagement. Erich Schmidt Verlag, Berlin, 2007; S. 125-142.1875

[4] W3C, “Web Services Architecture,,. Working Group Note, im WWW unter

http://www.w3.org/TR/ws-arch/wsa.pdf (15.03.08), 2003, S. 7

[5] E. Asfoura, N. Jamous, G. Kassam, and R. Dumke, “ E-mall as solution for marketing the federated ERP components on the basis of web services,, In: International review of business research papers . - Melbourne, Bd. 5.2009, 4, S. 478-490;

[6] J. Li-jie, M. Vijay, and S. Akhil, “ Analysis on Service Level Agreement of Web Services,,. Technischer Bericht, HP Laboratories Palo Alto, 2002.

[7] F. Leymannn, “ Web Service . Distirbuted Applikations without Limits. An outline,, in: 10th Conference on Database systems for basiness, Technology and web, Berlin et. Al. 2003, S. 4f.

[8] N. Brehm, and J. Marx Gómez, “ The Web Servicebased combination of data and logic integration on Federated ERP systems.,, In: 18th IRMA International Conference - Managing Modern Organizations with Information Technology, (IRMA2007), Vancouver, Canada, 2007.

[9] Networld Consulting (free report: Wozu Service Level Agreement (SLA)? http://www.vienna.cc/d/artikel/gratis_report_sla_service_le vel_agreement.htm. Access date: 3 October 2008.

[10] N. Brehm, J. Marx Gómez, and A. Ziesenitz, "Toolunterstützung bei der vermarktungsorientierten Entwicklung von Web Services als Bausteine komplexer betrieblicher Anwendungssysteme „, Multikonferenz Wirtschaftsinformatik 2008

[11] A. Bartelt, and W. Lamersdorf, “ Geschäftsmodelle des Electronic Commerce,, in: Informatik 2001 Wirtschaft und Wissenschaft in der Network Economy 2001, S. 902-908.
[12] P. Timmers, “ Business Models for Electronic Markets,, in: Electronic Markets 8(2), 1998.

[13] E. Asfoura, G. Kassem, C. Rautenstrauch, J.. M. Gómez, and N. Jamous,, " The classification of business model for the exchange of distributed components of Federated ERP Systems,,. In: Proceedings of the 3rd IEEE International Conference on information and communication technologies (ICTTA'08), Damascus, Syria, April 7 - 11, 2008.

[14] D. Rud, “ Preformancebewertung und-sicherheit von orchestrierten Serwiceangeboten,, in Verlag, Hamburg, 2009.

[15] M. Rohloff, “ Integrierte Informationssysteme durch Modellierung von Geschäftsprozessen,, . In König , W (Hrsg.) : Wirtschaftsinformatik 95- Wettbewerbfähigkeit , Innovation , Wirtschaftlichkeit, Physica , Heidelberg 1995.

[16] E. Asfoura, N. Jamous, and G. Kassam, , “ E-Mall as solution for marketing the federated ERP components on basis of web services,, ,In: Proceedings of the tenth International Business Research Conference . - World Business Inst., insges. 10 S.; 2009

[17] N. Brehm, J. Marx Gómez, and C. Rautenstrauch,: “ An Open Security Model for Web Service-based ERP Systems. , in: 4th Annual Security Conference, Las Vegas, USA, 2005.

[18] E. Asfoura;N. Jamous;G. Kassem and R. Dumke,: FERP mall role in FERP web servicesmarketingIn: International Conferenceon Information Society (iSociety). -Informations Society, IEEE, ISBN 978-09564263-3-8, (London, UK), 2010, S. 156-161.

[19] N. Brehm and J. Marx Gómez: Securing Federated ERP system clients. GITMA World Conference - Global Information Technology Management Association, Orlando, Florida, USA, 2006.

[20] N. Brehm and J. Marx Gómez.: Distribution of ERP system components and security considerations. 17th IRMA International Conference - Managing Modern Organizations with Information Technology. Washington D.C., USA, 2006. 